\title{
Design of Discrimination Model in Solico Organization
}

Hojat Alleh Vahdati

\author{
Assistant Prof, Faculty of Business Administration, Iorestan univercity, Khoram Abad, Iran
}

\section{Seied Keyvan Mousavi Cheshmeh Kaboodi}

PhD student in Human Resource Management, Department of Management, Faculty of lorestan univercity, Khoram Abad, Iran

\section{Doi:10.5901/mjss.2016.v7n3s3p212}

\begin{abstract}
The manpower is assumed as the foremost and most valuable elements in any organization as well as the paramount competitive advantage in knowledge-based economy. Discrimination between personnel of organization is one of the foremost problems regarding human resources at present time. It is a condition under which a different response is given to the personnel versus an identical event and under the same situation. Conducting this study aims at design of discrimination model in Solico Organization that was carried out by qualitative methodology and with exploratory- fundamental nature. The research data were collected through purposive- snowball sampling technique and based on in- depth interviews. According to method of database theory, data were analyzed after coding. Improvement of performance evaluation systems, salaries and bonus, promotion, transparent and fair appointments, paying more attention to private problems and welfare of personnel, and using flexible working techniques are some cases that may provide the grounds for moving in coordination with organizational goals and finally realization of organizational objectives in addition to affection by skills of directors with improvement of motivational system in personnel. It is recommended based on discrimination model in organization to consider the role of various factors in formation of discrimination in organization and to take systematic measures in this regard with conducting comprehensive studies.
\end{abstract}

Keywords: Disregard to organization, Discrimination, Lack of structural health in organization

\section{Introduction}

According to Longman Encyclopedia, term 'Discrimination' is defined in various and several forms of behaviors with similar objects and or individuals. Therefore, term 'Discrimination' is used for identifying the existing constraints in access to sources based on some of factors including gender and age etc (Wyzan, 1990). Discrimination in organization is crucially important since it determines the method of entry of personnel into organization and type of treatment with them and finally type of behavior of individuals in their life environment (Fakhro \& Brain, 1999). In fact, discrimination is an apparent symbol of injustice that may destructively affect mainly on occupational spirit of personnel at different levels. One of the important issues regarding discrimination is its direct relationship with social power structures; namely, those individuals and groups that enjoy lesser social power and influence are not benefitted from the identical rights compared to other persons and groups. In fact, discrimination is a form of unequal treatment with different individuals and groups in various fields and it may be exerted in different forms therefore perceiving and recognition of this behavior is relatively different as well (Dupre \& Barling, 2006). Perceived discrimination is directly related to individual impressions and internal and emotional borders between individuals. If the employer believes that the females are averagely unstable and less reliable then s/he tends further to exertion of discrimination against them and even though s/he knows that s/he has been wrong about some of personnel (Noroozi Seyed Hosseini et al, 2012). Inadequate information about efficiency of work applicants may cause gender and race affects on type of appointment of personnel by the employers similar to sign of efficiency. For instance, if rate of trust in a group of minority is at lower level and the employers also avoid from risk, the given group of minority will receive lower wage. This type of discrimination is called statistical discrimination (Akram, 2001). Despite of their potential and competency of them, lack of adequate utilization from the females at higher managerial levels may lead to their despair in doing their tasks and jobs properly and this is a type of indirect discrimination in work environment (Golparvar et al, 2011).

The efficient leaders are deemed as most fundamental and rarest sources in organizations. The failure of an organization in the field of achieving optimal productivity may be relatively attributed to inefficient management and 
leadership in that organization (Amiri et al, 2014). The management is tasked to present servicing patterns and standards in his/ her contact to the personnel that none of personnel feels sense of injustice and discrimination and to create quality of treatment with and paying attention to the customer. If the task of frontline personnel is to act such as champion of giving services then the role of director is also to guide the process of service as well (Iran Nejad Parizi, 2002). In this regard, in a survey under title of 'Interpretation of the parameters for communication skills of directors and their role in job satisfaction among personnel', Zarei Matin and Yousef Zadeh (2010) have expressed that the communication skills of directors have been effective in improvement of job satisfaction status of personnel and lacking sense of discrimination and injustice among them and if the components of communication skills are noticed in directors the organization will achieve the given objectives and with establishing appropriate relationship with personnel the directors will be benefitted from sustainable competitive advantage as a strategic potential (Zarei Matin \& Yousef Zadeh, 2010). Given that encouraging sense of discrimination among personnel in any organization is in fact spreading dissatisfaction of personnel and on the other hand dissatisfied personnel do not concern with advancement of organizational goals at all therefore the necessity for paying attention especially to status of personnel, emphasis on social justice, improvement of circumstances for workforce, and creating welfare for them are considered as motives for preparation and formulation of this study in Solico Organization (With more than thirty years of experience for activity in the field of producing the processed meat and dairy products, Solico Food Production Industrial Group is deemed as one of the most leading manufacturers of the processed foods and dairy products in Iran). In its growing trend of activity, Solico Group has established many companies including Amol Kalleh Dairy Products, Amol Kalleh Meat products, Tehran Solico meat products, KASELNOOSH, Baharangol, Ariss, Koochin, and Iranian Banichaw nationwide delivery group (Distribution Center Holding Companies) (Jamalzadeh, 2014).

\section{Research History}

Overall, gender discrimination has been posited as a serious problem during several past centuries. Garry Becker is one of the researchers who has dealt with this subject and has prepared his doctoral thesis in this regard and published a book titled 'Economy of discrimination' (Googerdchian et al, 2014). Neumark (2008) explored discrimination in Act Regarding Employment Age and challenge for aging of population in business market at USA and fighting against this discrimination in a survey. He focused on population aging challenge in USA economy during future decades. Neumark concluded that the fighting against discrimination at employment age most likely contributes to campaign against this challenge and it is assumed as encouragement for employment of older persons (Neumark, 2008). Bernard (1994) examined a group of Canadian citizens and found that difference in payable salaries to personnel might be assumed as the basic factor in creating sense of discrimination and finally quit working (self-employment) and this finding has been consistent with the results of previous researches (Reed 1986, Taylor 1996, Johansen 2000, and Hamarsted 2006) (Donald, 2012). Donald conducted a study titled 'Gender discrimination and dynamic self-employment among females in four western European countries' where the data have been collected in this study by the aid of household panels during years 1999-2001 that indicated what kind of relationship existed among discrimination and quit working (selfemployment). The results showed that those females whose income was lesser than their expectations (they felt sense of injustice in method of payments) have been more inclined to quit their work as employees (Donald, 2012). In an investigation with title of 'Discrimination in Police Organization', Brian (1999) concluded that there was some live discrimination in any organization including police organization but this phenomenon has suffered from some intensity and weakness over the years and similar to new rules it might affect on organizations (Fakhro \& Brian, 1990). The studies have shown that the justice processes and difference in method of treatment with personnel in organizations (discrimination) might influence in beliefs, emotions, motives, and behavior of personnel (Ames \& Archer, 1988). The presented evidences by Murphy (1993) signified that perception of the most distinct aspect of injustice i.e. discrimination might pave the way for tendency toward bias and destructive behaviors (Giddings, 2005). The given evidences by Golparvar (2012) also suggest that personnel in workplace may possess this attitude well that injustice and discrimination are required to be punished in some dimensions (Golparvar et al, 2012). Furthermore, in a study Mahoney et al (2010) came to the result that job satisfaction and perceived organizational justice in personnel of physical education departments of universities has been influenced by the perceived organizational supports. They also implied that as the rate of discrimination was lesser in these departments, job satisfaction of personnel would be increased consequently (Mahoney et al, 2010). In an investigation, Doherty et al (2005) concluded that organizational commitment in personnel of sporting organizations might be improved through supporting of directors from personnel. They have emphasized in lack of discrimination in sporting organizations and paying equal attention to females and males (Mahoney et al, 2010). With respect to the aforesaid issues and the conducted researches it can be implied that discrimination is not only summarized 
in tangible and physical activities, but there may some discrimination in intangible and indirect activities such as eyecontact of director and coach of team, dialogues, and even listening to utterances of various persons as well. Thus, recognizing the conditions and platforms for creating discrimination and actions and interactions which are executed in this regard may contribute to better perception of this phenomenon and certainly provide some strategies to control it. Hence, it is tried in this study to design discrimination model in Solico Organization and to give answers to these questions as follows: What are the causal conditions for discrimination in these organizations? Which are the platforms for creation of discrimination in these organizations? What are the intervening conditions in discrimination in these organizations? What are the characteristics of discrimination in these organizations? What are actions and interactions as well as consequences of discrimination in these organizations?

\section{Research Methodology}

Research statistical population includes directors (of branches, planning, sale, human resources, quality control, and financial units), sale sponsors in distribution branches in Solico Organization where due to ease of access to the directors, sale supervisors and personnel, Kermanshah Branch was selected and to prepare for sampling and conducting in-depth interviews, purposive sampling method and snowball sampling technique were employed. In this technique, a primary group was selected for interview and then next groups were introduced for interview by this group and sampling was continued as long as (16 interviews) the research achieved theoretical saturation and adequacy.

Demographic attributes of interviewees

\begin{tabular}{|c|c|c|c|c|}
\hline Row & Specifications & Modes & Quantity & Percent \\
\hline \multirow{2}{*}{1} & \multirow{2}{*}{ Gender } & Female & 3 & 19 \\
\hline & & Male & 13 & 81 \\
\hline \multirow{9}{*}{2} & \multirow{9}{*}{ Position } & Branch director & 3 & 19 \\
\hline & & Sale director & 3 & 19 \\
\hline & & Financial director & 1 & 6 \\
\hline & & Human resources unit director & 1 & 6 \\
\hline & & Quality control director & 1 & 6 \\
\hline & & Planning director & 1 & 6 \\
\hline & & Sale supervisor & 4 & 25 \\
\hline & & Treasurer & 1 & 6 \\
\hline & & Achiever & 1 & 6 \\
\hline \multirow{3}{*}{3} & \multirow{3}{*}{ Education } & Associate's degree & 2 & 13 \\
\hline & & Bachelor's degree & 10 & 63 \\
\hline & & Master's degree \& higher & 4 & 25 \\
\hline \multirow{3}{*}{4} & \multirow{3}{*}{ Work background } & Less than 2 years & 3 & 19 \\
\hline & & $2-4$ & 6 & 38 \\
\hline & & More than 4 years & 7 & 44 \\
\hline
\end{tabular}

The present research was carried out with exploratory nature and in order to develop the existing knowledge and recognition about discrimination in organizational field. In qualitative methodology, often emerging methods, open-ended questions, and content analysis and final conclusion have been achieved according to findings (Koozehchian \& Heidari, 2012). In this study, method of database theory was utilized. By means of this method researcher can extract systematically the commonalities among enormous volume of data and based on which theorize in field of his/ her study. This strategy enjoys a type of inductive approach. Namely, the theory formation trend in this strategy is to move from the parts toward whole. The major objective of this method is to interpret a phenomenon through identifying key elements (concepts, categories, and propositions) of that phenomenon and then classification of the relations between these elements inside the platform and process of that phenomenon. Production and creation of concepts, categories, and propositions are also a cyclic- iterative process. In this technique, instead of proposing them in forms of specific hypotheses, research questions should be open-ended and general and the resulting theory should interpret the phenomenon under study (Amiri et al, 2014). There are three overlapping processes in analytical process of fundamental conceptualization theory including Open Coding, Axial Coding, and Selective Coding. Data collection and analysis was done simultaneously and consciously in execution of research and data collection was implemented in order to form continuous collection trend. Some opportunities were provided for researcher by doing this task so that to increase rate of 
adequacy of suitable categories (Danayee Fard, Alvani \& Azar, 2012).

\section{Results of Research}

Whereas this study lacks any hypothesis and there are only some research questions thus after study and exploring theoretical bases, raw data were derived inductively from in-depth interviews with the elites and experts and they were systematically analyzed according to database theory. An example of data analysis method is as follows:

An example of method open- coding of research data

Interviewee: dairies branch director (Mr. Fotoohi)

\begin{tabular}{|c|c|c|}
\hline Category & Concept & Codes \\
\hline \multirow{6}{*}{ Relation or discipline } & \multirow{4}{*}{ Influence } & Nepotism upon appointment and employment \\
\hline & & Difference in social and political and organizational status \\
\hline & & Influence and power (political influence) \\
\hline & & Connection to higher officials \\
\hline & \multirow[b]{2}{*}{ Paying attention to friends } & Preference of friendship and relative relationship in organization \\
\hline & & $\begin{array}{l}\text { Difference in method of talking and further intimacy with } \\
\text { personnel }\end{array}$ \\
\hline \multirow{8}{*}{ Skills \& occupational ethics } & \multirow{2}{*}{ Potential of personnel } & Non- identical skills and potentials in personnel \\
\hline & & Non- compliance of expectations and performance \\
\hline & \multirow{4}{*}{ Characteristics \& occupational ethics } & Lack of good morality in organizational environment \\
\hline & & Rate of cooperation in team-works \\
\hline & & Lack of conveying one's knowledge to colleagues \\
\hline & & Mistreatment \\
\hline & \multirow{2}{*}{ Individual responsibility } & Lack of sense of responsibility \\
\hline & & Lack of follow-up and responsiveness about issues \\
\hline \multirow{8}{*}{$\begin{array}{l}\text { Organizational } \\
\text { management style }\end{array}$} & \multirow{2}{*}{ Director's attitude } & Giving facilities and resources to specific group \\
\hline & & Granting bonus and rewards and facilities \\
\hline & \multirow{3}{*}{ Director's taste } & Difference based on physical dress \\
\hline & & Affection to certain personnel and groups \\
\hline & & Difference in types of contracts with personnel \\
\hline & \multirow{3}{*}{ Leadership and management style } & Lack of properly control by director over personnel \\
\hline & & Confirmation in group interactions \\
\hline & & $\begin{array}{l}\text { Creating intimate climate for insider personnel and formation of } \\
\text { despotic climate for the rest }\end{array}$ \\
\hline \multirow{3}{*}{ Work background } & \multirow{3}{*}{$\begin{array}{l}\text { Experience and acquaintance with work } \\
\text { (work experience) }\end{array}$} & Working in various positions \\
\hline & & Experience in similar industries \\
\hline & & Having work experience \\
\hline \multirow{4}{*}{ Ethnicity } & \multirow{2}{*}{ Geographic conditions } & Local personnel \\
\hline & & Having suitable appearance proportional to the given city \\
\hline & \multirow{2}{*}{ Cultural conditions } & Familiarity with local dialect \\
\hline & & Familiarity with customs in city of workplace \\
\hline \multirow{5}{*}{ Characteristics of personnel } & \multirow{2}{*}{ Spirits (features) of personnel } & The relevant spiritual feature to business and organization \\
\hline & & Personality of personnel \\
\hline & \multirow{3}{*}{ Individual's imaginations from organization } & Loyalty to organization \\
\hline & & Organizational knowledge and awareness of personnel \\
\hline & & Lack of on-time presence in organization \\
\hline \multirow{4}{*}{$\begin{array}{l}\text { Organizational bases and } \\
\text { principles }\end{array}$} & \multirow{2}{*}{ Rewarding system } & Lack of transparency in rewarding structure \\
\hline & & Lack of transparency regarding criteria of promotion \\
\hline & \multirow{2}{*}{ Organizational regulations } & Organizational framework to control personnel \\
\hline & & Organizational framework about work conditions and shifts \\
\hline
\end{tabular}

Axial coding includes the process of relevance of categories and subcategories and linking categories at level of attributes and dimensions. At this phase, categories, attributes, and resulting dimensions from open-coding are codified and placed in their positions in order to create the generative knowledge about the given relations. 
An example of method of axial-coding of research data

Interviewee: Dairies branch director (Mr. Fotoohi).

\begin{tabular}{|l|l|}
\hline Axial coding & \\
\hline \multirow{2}{*}{ Work climate poisoning } & Relation or discipline \\
\cline { 2 - 2 } & Ethnicity \\
\hline Lack of structural health & Organizational bases and principles \\
\hline \multirow{3}{*}{ Intraorganizational factors } & Work background \\
\cline { 2 - 2 } & Characteristics of personnel \\
\cline { 2 - 2 } & Skills and occupational ethics \\
\hline Management inconsideration & Organizational management style \\
\hline
\end{tabular}

In open-coding process, the analyst creates their categories and attributes and then tries to identify how the categories vary along with the determined dimensions. In axial coding process, categories are systematically improved and linked with subcategories. Nevertheless, these are not yet considered as the main categories in order to be integrated finally to form greater theoretical arrangement so that the results of study to achieve theoretical form. The selective coding includes integration process and improvement of categories given in the final model.

To determine trustworthiness of data (which is equivalent to validity and reliability in quantitative researches), two methods of recoding were utilized by another researcher. $10 \%$ of all of pages of the conduced coding were put at disposal of another researcher. SCOT coefficient indicates the rate of compliance of coding at two phases which are derived for main categories, including respectively organizational poisoning (0.87), lack of structural health (0.81), discrimination (0.90), internal factors (0.83), management inconsideration (0.84), and disregard to organization (0.82) that shows the favorable consistency of coding. Similarly, member-checking technique was employed to determine approval (Koozehchian \& Heidari, 2012). Coding samples and final model were put at disposal of interviewees and they implemented their comment for them and finally they verified research general model.

\section{Results and Findings of Research}

Based on the posited procedures in section of research methodology, the final model is as follows. To interpret phenomenon of discrimination in Solico Organization in this model, six classes were determined each of which has some relationships with each other. The phenomenon of discrimination is placed in axial class of this model per se. This category is the same as conceptual label that was considered for the created framework or design. Given that in this study discrimination phenomenon has been studied in this survey after collection of data and analyzing them at opencoding phase and reviewing the given attributes, discrimination class was selected as the axial class. The next class is causal conditions. These conditions cause creating and developing of phenomenon or axial class. Among produced classes. Poisoning of organizational climate along with its features was assumed as causal conditions. The governing platform is the next class. This class is called to specific conditions that create the need platform for axial phenomenon. These conditions are composed of a group of contextual concepts or variables, which have been called under title of lack of health in organizational structure. This class affects the actions and interactions. The next class is intervening conditions which include general conditions composed of a group of mediator and intermediary variables and they influence in the class of actions and interactions. This class is called Intraorganizational factors in the model. The next class is actions and interactions that represent purposeful behaviors, activities, interactions, which are placed in consequences of axial class and under influence of intervening conditions and the governing platform. This class has been called inconsideration of management in the model. The last class locating in the model includes consequences, which are called under title of disregard to organization. This class denotes outcomes and consequences, which are created due to taking strategies and behaviors. 


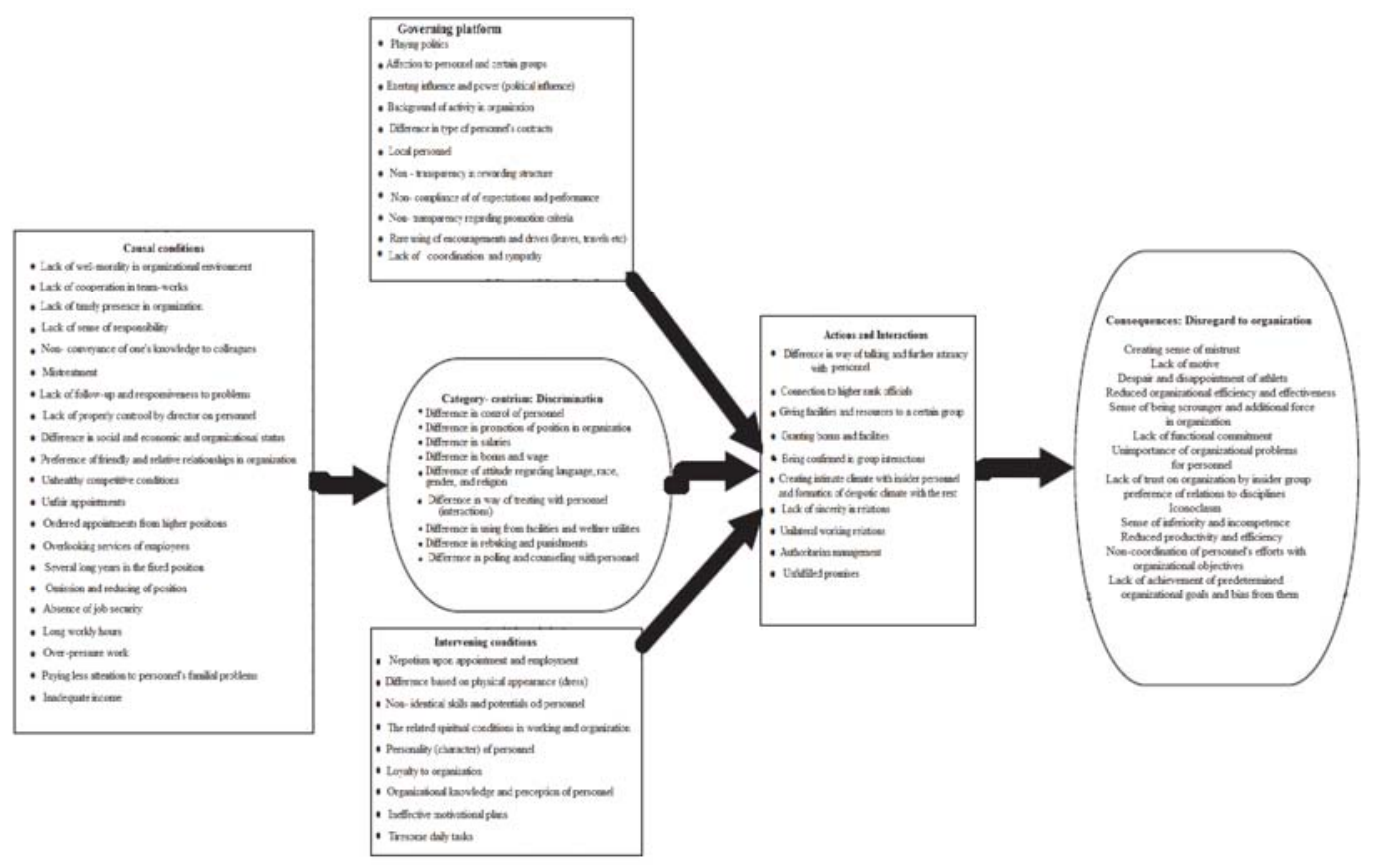

Model of discrimination in Solico Organization

\section{Discussion and Conclusion}

The organization is a social system that its life and stability depends on presence of a strong link between its constituent elements and parts (Saatchi, 2000). With termination of period of domination by classic and instrumentalist paradigms in management, more attention has been paid to human and his/ her existence dimensions by management and as a result the related researches to organizational behavior have been further deepened and a domain under title of occupational ethics has been proposed among many experts (Tavakoli et al, 2009). The occupational ethics enjoyed several effects among personnel and sponsors. The presence of equitable and fair outlook in organization is one of the most prominent effects of occupational ethics. In fact, equality in various social- economic dimensions is especially important not only as an ethical necessity, but also as a path toward cultivation and development of nations. There are some undeniable evidences that show that equality and parity causes acceleration of economic growth, strengthening of governments, reduced poverty, and creating social securitizing throughout the world (Ames \& Archer, 1988). Since several recent decades, justice in workplace has been used as interpretive variable for many events and accidents in different studies. These phenomena are related to perception of individuals or groups of observance of equity and justice in organizational behaviors and decisions at different levels and behavioral and perceived reactions to these perceptions. The justice is considered as the perceived organizational justice in workplace. Adding term 'perceived' to phrase of organizational justice refers to phenomenological nature of justice in subjective and cognitive climate in each of individuals (Holmes, 2011).

Herzberger expressed that giving reward to personnel and or compelling them for working in workplace is deemed as motive for directors not personnel but what it done, is further effort of personnel that is the same as mobility. Therefore, Herzberger assumes creating motive as practical by the aid of these internal processes and not external rewards. For this reason, he proposes job enrichment instead of occupational empowerment (Mahram \& Dashti Rahmat Abadi, 2009). Paying attention to requirements of personnel in organization and importance and preference they attach for each of them deserves a lot of attention and awareness about motivational issue for personnel is especially necessary for the organizational directors where it is in fact searching for the reason and cause of movement and behaviors of organizational members. On the other hand, subject of recognition of requirements and motivational factors of personnel in organization depends on specific conditions in that organization and it should be taken into special consideration since 
manpower is deemed as the most valuable assets for organization and performance of personnel is directly and indirectly related to organizational goals and outlook. Nevertheless, in some organizations the working motives, encouragement, punishment and appreciation for good working are not highly noticed. The directors have made their own highly involved in various issues that they have no time and opportunity to deal with this subject and or they never pay any attention to this issue. A model was proposed for interpretation of discrimination in Solico Organization in this study thereby one can identify well the phenomenon of discrimination in organization. In this model, difference in control of personnel, difference in promotion of status in organization, difference in salaries, difference in bonus and wages, difference in attitude to language, race, gender, and religion, and difference in method of treatment with personnel (interactions) have been identified as main elements of discrimination. The racial, gender, religious, and lingual differences play more prominent role in this model. As Broyles and Cane (2010), Holmes (2011), and Moosavi and Rahverdi (2004) have mentioned in their studies (Broyles, Keen, 2010; Moosavi \& Rahverdi, 2004) ethnic and gender differences in discrimination might create some conditions under which personnel with different lingual and racial conditions to feel different sense in organizational status and they might have identical rights. In addition, females have always criticized unequal and discriminatory conditions in various organizational fields and argued that these conditions are not duly addressed. In the discrimination model that is proposed for Solico Organization, some factors have been identified as causal conditions including lack of good morality in organizational environment, difference in rate of cooperation with organization, lack of on-time presence in organization and branches, lack of sense of responsibility, lack of conveying their knowledge to colleagues, mistreatment, lack of follow-up and responsiveness about the issues, lack of proper control over personnel by directors, difference in working conditions, preference of friendship and relatives relations in organizational field where some part of these conditions are related to measures and actions of personnel and the other part is attributed to directors. It can be implied about this phenomenon that theorists in classic management believe in that cooperation is assumed as vital in organizations and at least it is a very favorable objective. One of the reasoning cases of this school is that the organization will not possess any certain moving path without cooperation for a goal and it will be entrapped by rivals (Danayee Fard, 2013).

Based on this model, of Intraorganizational factors, which are called as intervening factors, one can refer to nepotism upon recruitment of personnel, difference based on apparent dress, non- identical skills and potentials of organizational personnel, and the related conditions of spirit for occupational and organizational conditions. In this sense, creating motive in personnel for further follow-up of tasks and improving their skills and potentials is one of the most original tasks for directors in organization; namely, personnel may try harder and they attend in workplace routinely and try for practicality of goals and making organizational decisions.

The actions and interactions take place regarding discrimination and they are called inconsideration of organizational management including some components such as difference in way of talking and further intimacy with axial personnel and so-called sacred cows, connection to higher rank officials, giving facilities and resources to a specific group, granting reward and facilities and approval in group interactions. When discriminatory behaviors take place the director may provide some facilities for them in way of his/ her interactions with the given personnel and this is led to affect on satisfaction of other personnel. Whereas satisfaction is the intrinsic part of participation in any organization, regardless of sense of satisfaction the personnel tend to other resources for acquisition of success and enjoyment and this may cause their organizational commitment to be reduced (Danayee Fard, 2013). These personal interests are threatened if discriminatory behaviors take place and even they may be destroyed. Social stresses are considered as social expectations and norms that create sense of compulsion to continue activity. These requirements may be followed by negative consequences if they originated from occurrence of negative behaviors. And finally opportunities for participation are assumed as valuable chances which are achieved only through continuance of participation (Zaccaro et al, 2001).

The consequences and results of discrimination model that is called disregard to organization, include some components such as creating sense of mistrust, lack of motive, despair and disappointment of personnel, reduced organizational effectiveness and efficiency, sense of being scrounger and extra in organization, lack of functional commitment, unimportance of organizational problems for personnel, lack of organizational trust in party other than insiders, priority of relations to disciplines, iconoclasm, and sense of inferiority and incompetence. All of these element may exert destructive and harmful effect on organization and may strengthen indifference to organization since human resources is the formative, designer, and impetus factor in that organization where this issue is followed by necessity for addressing human resources and subjects regarding creating their motive in organizations such as sense of equality. One of the relevant theories about justice and equality has been posited by Stacy Adams (Golparvar et al, 2011). It has been based on this assumption that individuals like to be treated fairly and with justice. Given that the equality theory is one of the subjects which its theoretical basis resulted from processes of social comparison, it necessitates for 
organizational directors to notice constantly processes of social comparisons and as a result to look at motivation as a variable and dynamic factor (Amuzadeh Mehdiraji \& Razavi Hajji Agha, 2010). Based on theory of equality, justice is administered in social relations when rewards, punishments, and allocated resources play role in interventions with respect to their portion for any person (Dupre \& Barling, 2006).

With respect to ever-increasing changes in human community and change in expectations of beneficiaries, it seems the presented model in this study can proved the ground for interpretation of discrimination in various organizations and enable directors and practitioners to extract designs and measures for improvement in addition to diagnosis of the way of organizational management comprehensively and evaluate their position in development process and empowerment of personnel. In addition to possess structure of a comprehensive system, the proposed model in this study includes modern orientation in discrimination models and provides development, growth, and excellence of organization in creating sustainable balance in interests of beneficiaries (owners, shareholders, personnel, customers, suppliers, and local community) in order to improve organizational productivity. Rather than benefitting from the adequate theoretical support, this model has been refined based on comments from the experts as well. Similar to any other organization, Solico Organization includes several and various beneficiaries where the most distinct group of these beneficiaries are owners and shareholders and other beneficiaries comprise of personnel, customers, suppliers, and local community (Mintzberg et al, 1976). These beneficiaries do not agree unanimously in that how the organization could give services to them in best possible form. This lack of unanimity causes that there is some possibility for ignoring interests of a series of beneficiaries upon taking strategic measures by high- ranking directors so this may lead to creation of sense of dissatisfaction and injustice among organizational personnel. Therefore, it is suggested to observe the following cases to prevent from this issue:

1- Separation and differentiation of interests of some beneficiaries for whom it is possible for the organization to fulfill their requests. By doing this task, a part of organization becomes responsible for meeting requirements of specific part of beneficiaries and in this way other parts of organization will be tasked to address needs of other beneficiaries. In other words, organization becomes specialized in managing several conflicting demands.

2- Paying combinatorial attention: This means at present the organization addresses the concerns of specific group of beneficiaries and after a time period it deals with interests of other beneficiaries. This technique may create this confidence in personnel and beneficiaries that their interests and expectations will be finally met some day.

3- Taking satisfactory approach: It denotes that all of beneficiaries are kept relatively satisfied all the times. Namely, way of addressing is in such a way that it is not restricted to certain times and groups, which may be led to sense of inequality.

\section{References}

Akram,k.(2002).Examine the phenomenon of wage discrimination against women in the labor market of Iran, Master Thesis, Institute for Research in Planning and Development, pp: 89-110.

Amiri,M. Norooziseyedhosini,R. Khatibzadeh,M.azadan,m. smayli,m.(2013) Introduction to qualitative research methods in sport. Tehran, Tehran University Press, pp: 233- 235.

Andro,P.Pederson,P. Makoie,Ch.(2012). Design and research methods in sport management, translation Kvz-h־Chyan Hashim, R. H. Year, Akbar Heidari, Tehran. Sure, pp: 29. 30.

Tavakoli,Z. Abedi,M.Salehniya,M.(2009).The effect of training on increasing organizational commitment organizational citizenship behavior. Landscape Management, №. 33, pp. 105-124.

Jamalzadeh,A.(2013).The system of employee participation, Sci message Svlykv, the fifth year, No. XVII, p. 6.

Ghezavi,A. Gogerdchian,A. Tabibi,k. (2014).The effect of the gender earnings gap in the employment of women in Iran (2011-1391), Journal of Civil Engineering, No. 17, pp: 145-169.

Saatchi,M.(2000).Work Psychology, Tehran Institute of editing publishing.

Zareimateen,H \& Yosetzadeh,S.(2010). Explain the communication skills of managers and their role in job satisfaction. Journal of Educational Psychology, Islamic Azad University Branch, the first year, No. 2, Ss29-48

Hapson,B. Jak,A. \& Mik,D.(2002).Service management (customer Ygrayy culture), translated by Iran Nzhadparyzy, Mehdi. Tehran: Users

Amozadeh,H. \& Razavi,H.(2008). Herzberg's two-factor theory, valid or Atbar.mjlh policy number 218.

Golparvar,M.Vaseghi,Z.\& Mosahebi,M.(2012).Model organizational injustice, stress and emotional burnout in nurses Zn.fslnamh Iran Occupational Health, Vol. 9, №. 3, pp. S95-83.

Mahram,B. Dashtirahmat Abadi,M.(2009). The impact of leadership style on employees' sense of equality of Mashhad University of Medical Sciences. Health Management magazine, No. 12, p. 38. 
Mousavi,F \& Rahvari,K.(2004). A comparative study of the working conditions of women and young people in Japan, South Korea, India, Egypt, England, Iran. Faculty of Law and Political Science at Tehran University, No. 64, pp: 187-218.

Nooroozisyiedhosini,R. Fathi,H \& Brojerdi,S.(2012). The effect of perceived leadership behaviors coaches and sports commitment, achievement motivation and satisfaction of the Premier League's judo fighters, Journal of Sport Management, No. 16, pp: 189206

Hach, M. (2013) The theory of modern and postmodern symbolic interpretation. (C. Knowledge of the translator) Tehran friendly publications publish Fifth, Sixth Edition, p. 501.

Danayyfrd,H. Alvani,M \& Azar,A.(2012). Qualitative research methodology in management: a comprehensive approach, Second Edition, First Printing, Tehran. Saffar, pp: 132-130.

Ames, C., \& Archer, J. (1988). Achievement Goals in the Classroom: Students Learning Strategies and Motivation Processes. Journal of Educational Psychology, 80, 260-267.

Bodvarsson . O, Papps . K, Sessions. J. (2014) Cross-assignment discrimination in pay: A test case of major league baseball, Labour Economics, (28) 84-95.

Broyles. P., Keen. B. (2010), Consumer discrimination in the NBA: An examination of the effect of race on the value of basketball trading cards, The Social Science Journal (47): 162-171.

Dupre K \& Barling. J. (2006) Predicting and preventing supervisory workplace aggression. J Occup Health Psychol; 11 (1): 13-26.

Giddings. L. (2005) Health disparities social injustice, and the culture of nursing. J Nursing Research, 54 (5): 304-312.

Golparvar. M, Rafizadeh. P. (2010) The role of justice on attitude toward organization and satisfaction with complaint handing. Ethics in Science \& Technology, $4(3,4): 54-65$.

Holmes, P. (2011),New evidence of salary discrimination in major league baseball, Labour Economics, (18): 320-331.

Mahoney . F. Daniel, Hums A, Andrew .P.S., Dittmore .W. (2010). Organizational justice in sport . Sport Management Review, Volume 13, Issue 2, PP: 91-105.

Zaccaro, S. J., Rittman, A. L., \& Marks, M. A. (2001). Team Leadership. The Leadership Quarterly, 12, 451-483.

Donald R. (2012) Gender discrimination and self-employment dynamics in Europe. The Journal of Socio-Economics 41 (2012) 153- 158.

Fakhro H \& Brian H. (1999),"Discrimination in city police departments", Equal Opportunities International, Vol. 18 Iss 5/6 pp. 88 - 93.

Neumark D. (2008) The Age Discrimination in Employment Act and the Challenge of Population Aging. NATIONAL BUREAU OF ECONOMIC RESEARCH; 12(1): 16-26.

Wyzan, M. (1990), The Po litical Econ omy of Eth nic Dis crimination and Af firmative Ac tion, Praeger Pub lishers,new York,16.

Mintzberg ,H, Raisinghani ,D, Theoret ,A. (1976) The structure of unstructured decision. Administractive science quarterly, 46-75. 